\section{Sika steigert \\ Gesamtumsatz um fast 6 Prozent}

—ür das vergangene Jahr meldet Sika - ein Umsatzwachstum um 5,8 Prozent auf CHF 4,82 Mrd.. Das höchste Wachstum verzeichnete das Unternehmen in Lateinamerika mit 17 Prozent in Lokalwährungen, begünstigt durch kontinuierliche Investitionen und den Ausbau von Produktionskapazitäten in der ganzen Region. In Nordamerika realisierte Sika eine Steigerung des Umsatzes in Lokalwährungen von 9 Prozent dank hoher Nachfrage an Bausanierungen und in Asien/Pazifik konnte der Umsatz in Lokalwährungen um 6,8 Prozent gesteigert werden. Hier profitierte Sika von einer starken Umsatzexpansion in Südostasien, einer stabilen Auftragslage in Japan und einer deutlichen Erholung in China im zweiten Halbjahr. Die Region IMEA (Indien, Naher Osten und Afrika) konnte in Lokalwährungen um 7,7 Prozent zulegen.

In Europa wirkten sich die Verschuldungsproblematik und die Eurokrise negativ aus. Dies führte zu einer rückläufigen Volumenentwicklung in den meisten europäischen Märkten. Die Region Europa Nord verzeichnete in Lokalwährungen ein negatives Wachstum von -4 Prozent, die Region Europa Süd ein Wachstum von 1 Prozent. Hier ergibt sich nach Abzug des positiven Akquisitionseffekts ein rückläufiges Wachstum von -7 Prozent.

Der Umsatzanteil, den Sika in den Schwellenländern erzielten konnte, liegt bei 37 Prozent (Vorjahr: 36 Prozent).

Mit Produkten für die Bauindustrie steigerte Sika im Geschäftsjahr 2012 den Umsatz in lokalen Währungen um 4,2 Prozent bei einem Akquisitionseffekt von 3,4 Prozent. Bei den Produkten für die industrielle Fertigung betrug die Umsatzsteigerung in lokalen Währungen 9,4 Prozent bei einem Akquisitionseffekt von 3,5 Prozent.

\section{Industrielles}
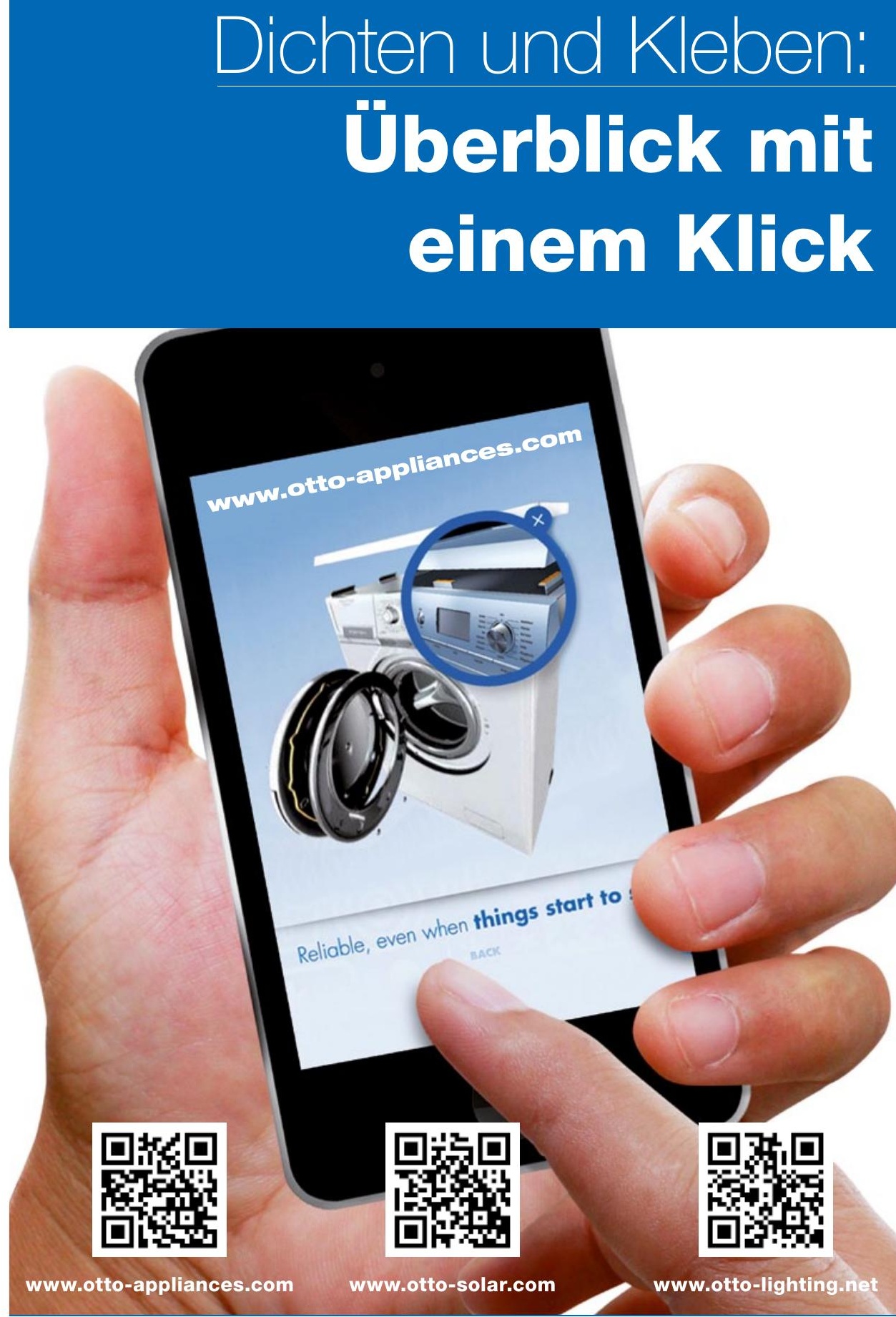

High-tech-Dicht- und Klebstoffe von OTTO übernehmen heute bereits eine Vielzahl von Aufgaben in industriell hergestellten Produkten. Im Internet zeigen wir Ihnen, wo und wie. Surfen Sie doch einfach einmal auf unseren Special-Industries-Websites vorbei. Oder nutzen Sie die QR-Codes für eine schnelle Verbindung via Smart-Phone.

OTTO - Immer eine gute Verbindung! 